Article

\title{
A Novel Route for Agarooligosaccharide Production with the Neoagarooligosaccharide-Producing $\beta$-Agarase as Catalyst
}

\author{
Chengcheng Jiang ${ }^{1}$, Zhen Liu ${ }^{1, *}$, Jianan Sun ${ }^{1}$, Changhu Xue ${ }^{1,2}$ and Xiangzhao Mao ${ }^{1,2, * \mathbb{D}}$ \\ 1 College of Food Science and Engineering, Ocean University of China, Qingdao 266003, China; \\ cz941220@163.com (C.J.); sunjianan@ouc.edu.cn (J.S.); xuech@ouc.edu.cn (C.X.) \\ 2 Laboratory for Marine Drugs and Bioproducts of Qingdao National Laboratory for Marine Science and \\ Technology, Qingdao 266237, China \\ * Correspondence: liuzhenyq@ouc.edu.cn (Z.L.); xzhmao@ouc.edu.cn (X.M.); \\ Tel.: +86-532-8203-1360 (Z.L.); +86-532-8203-2660 (X.M.); Fax: +86-532-8203-1789 (X.M.)
}

Received: 28 January 2020; Accepted: 9 February 2020; Published: 10 February 2020

check for updates

\begin{abstract}
Enzymes are catalysts with high specificity. Different compounds could be produced by different enzymes. In case of agaro-oligosaccharides, agarooligosaccharide (AOS) can be produced by $\alpha$-agarase through cleaving the $\alpha$-1,3-glycosidic linkages of agarose, while neoagarooligosaccharide (NAOS) can be produced by $\beta$-agarase through cleaving the $\beta$-1,4-glycosidic linkages of agarose. However, in this study, we showed that $\beta$-agarase could also be used to produce AOSs with high purity and yield. The feasibility of our route was confirmed by agarotriose (A3) and agaropentaose (A5) formation from agaroheptaose (A7) and agarononoses (A9) catalyzed by $\beta$-agarase. Agarose was firstly liquesced by citric acid into a mixture of AOSs. The AOSs mixture was further catalyzed by $\beta$-agarase. When using the neoagarotetraose-forming $\beta$-agarase AgWH50B, agarotriose could be produced with the yield of $48 \%$. When using neoagarotetraose, neoagarohexaose-forming $\beta$-agarase DagA, both agarotriose and agaropentaose could be produced with the yield of $14 \%$ and $13 \%$, respectively. Our method can be used to produce other value-added agaro-oligosaccharides from agarose by different agarolytic enzymes.
\end{abstract}

Keywords: agarose; agarase; agarotriose; agaropentaose; expression

\section{Introduction}

Agarose is a polysaccharide which is widely restricted to the red algae, and it is composed of D-galactose (D-gal) and 3,6-anhydro-L-galactose (L-AHG) with alternate $\beta$-1,4- and $\alpha$-1,3-glycosidic linkages [1,2]. Agaro-oligosaccharides are originated from agarose and can be divided into agarooligosaccharide (AOS) and neoagarooligosaccharide (NAOS); the non-reducing end of AOS is D-gal while the NAOS taking the L-AHG as non-reducing end. In recent years, considerable studies demonstrated that AOSs possess a variety of physiological activities, such as prebiotic properties, antioxidant activity, $\alpha$-glucosidase inhibition activity, anti-inflammatory effects, hepatoprotective effects and potential protective effects against neurotoxicity [3-6], which suggested that AOSs have the potential to be used for food, cosmetic and pharmaceutical industries.

Agaro-oligosaccharides can be produced by agarase, which is divided into $\alpha$-agarase (EC 3.2.1.158) and $\beta$-agarase (EC 3.2.1.81) based on their cleavage actions [7,8]. $\alpha$-Agarase could act on the $\alpha-1,3$-glycosidic linkages of agarose to prepare even-numbered AOSs [9-11], while $\beta$-agarase could act on the $\beta-1,4$-glycosidic linkages of agarose to prepare even-numbered NAOSs, such as the $\beta$-agarase Aga16B, originating from Saccharophagus degradans 2-40T and can be used for obtaining neoagarotetraose (NA4) and neoagarohexaose (NA6) [12]. 
In this study, a novel route was established to produce AOSs by using the NAOS-producing $\beta$-agarase. More specifically, the citric acid hydrolysis was used to produce AOSs with high degrees of polymerization (DP). Furthermore, NA4-forming $\beta$-agarase AgWH50B from Agarivorans gilvus WH0801 (GenBank accession no. CP013021.1) or NA4, NA6-forming $\beta$-agarase DagA from Streptomyces coelicolor A3(2) was used to hydrolyse the AOSs with high DP for preparation of agarotriose (A3) or A3 and agaropentaose (A5) [13-15], respectively. More importantly, our route is also suitable for preparing odd-numbered AOSs with higher DP, such as A7, A9, and so on.

\section{Results and Discussion}

\subsection{Feasibility of the Chemical-Biological Route}

Our research route was shown in Figure 1. Under the mild acid condition, AOSs were predominantly produced because the $\alpha-1,3$-glycosidic linkages of agarose were preferentially cleaved $[8,16]$. In previous reports, sulfuric acid, hydrochloric acid, and acetic acid were often used for obtaining AOSs from agarose or agar [17,18]. Citric acid, an organic acid that can be used in food industry [19], also can be used for AOSs production [3,20]. However, these produced AOSs have different DPs. As shown in step II of Figure 1, if $\beta$-agarase can act on the $\beta$-1,4-glycosidic linkages of the AOSs produced after liquefaction of agarose, an odd-numbered AOS could be cut off from the non-reducing end. Furthermore, because of the specificity of enzyme, the cut-off AOSs would have the same DP. Therefore, plenty of AOSs with special DP would be produced by a two-step chemical-biological reaction. To verify the feasibility of this route, the AgWH50B and DagA were used to act on A7, A9, respectively. Results showed that A3, NA4 and neoagarobiose (NA2) were generated from hydrolysis of A7 or A9 by AgWH50B; A3, A5, NA2 and NA4 were generated from hydrolysis of A7 or A9 by DagA (Figures 2a and 3). According to the composition of A7 reaction products, we could speculate the reaction mechanism of AgWH50B towards A7. Obviously, AgWH50B could cleave $\beta 2$ to create $\mathrm{A} 3$ and NA4, but it could cleave $\beta 3$ as well in a small degree to create A5 and NA2, and A5 could be further degraded into A3 and NA2. The degradation of A9 has similar results. AgWH50B first cleaves $\beta 2$ and $\beta 4$ to create A3, NA6 and A7, NA2 separately. In addition, a slight cleavage towards $\beta 3$ could create A5 and NA4. In the process of further reaction, A5 was degraded into A3 and NA2 while NA6 was degraded into NA4 and NA2. DagA could help us prepare A3 and A5 simultaneously. There exist two cutting sites of $\beta 2$ and $\beta 3$ to the same extent when using $A 7$ as reaction substrate. Therefore, we could get A3, A5, NA2 and NA4 from the products. However, when we change the substrate to A9, DagA shows a preference towards $\beta 3$ to create A5 and NA4; after that, DagA could cleave $\beta 2$ in a relative weak way, which could create a small quantity of A3 and NA6. Furtherly, NA6 could be catalyzed to create NA4 and NA2 (Figure $2 b$ ). These results demonstrated that there is an easy and feasible method for odd-numbered AOSs' production. 


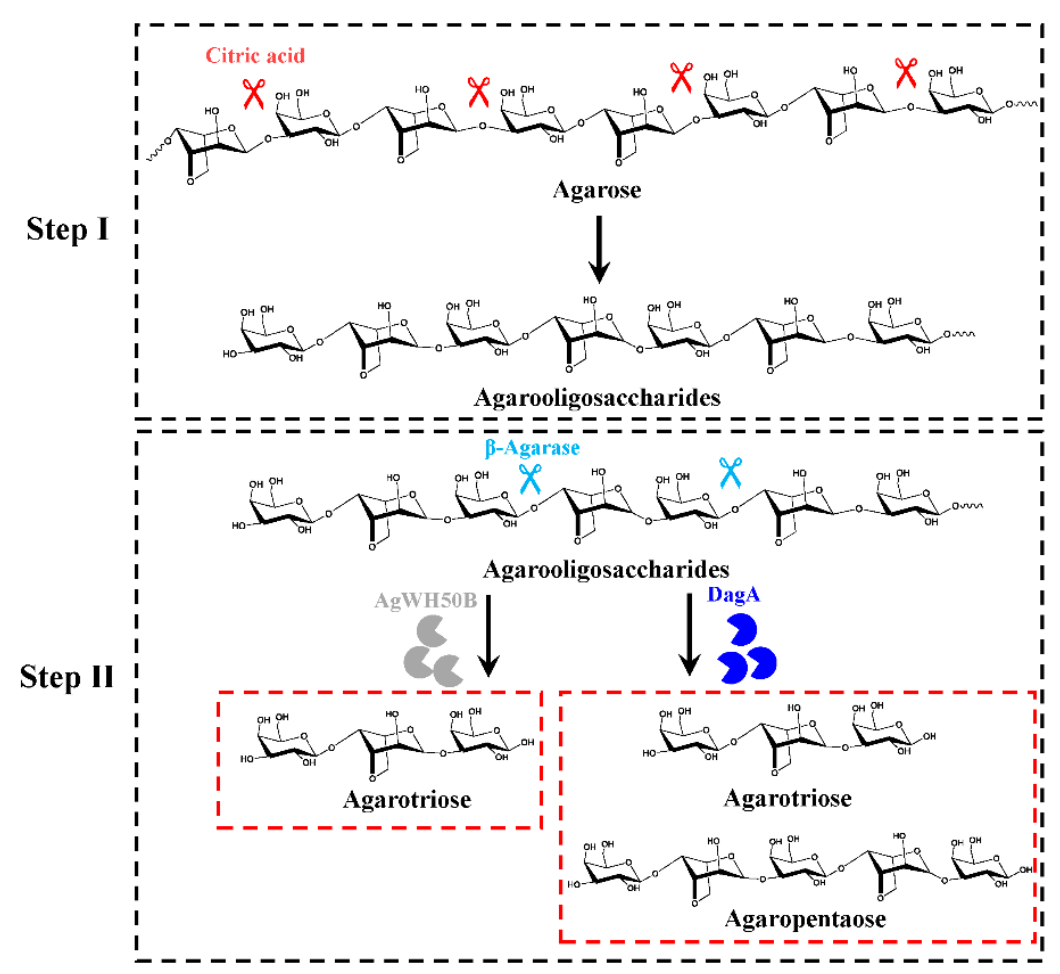

Figure 1. Technical route for preparation of A3 or both A3 and A5 by acid hydrolysis followed by enzymatic hydrolysis.

a

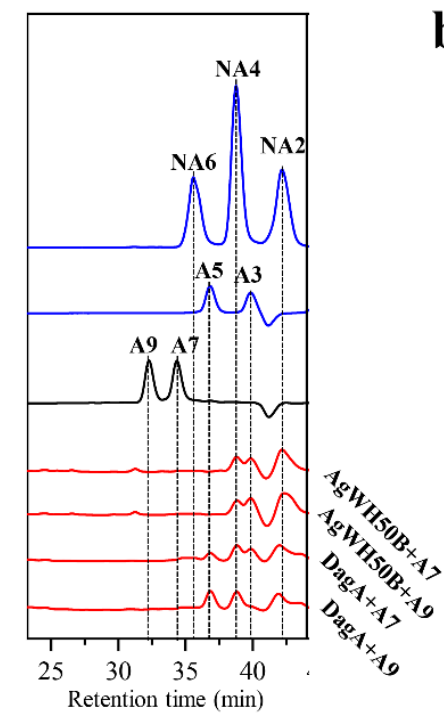

b

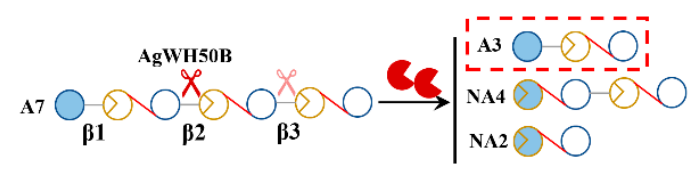

B1

$\underset{\beta 1}{B 2}$

$\beta 1$

Annotation:

(e) 3,6-anhydro-L-galactose $\backslash u$-1,3-linkage

D-galactose

Nonreducing end

Figure 2. HPLC analysis of enzymatic production of agaroheptaose (A7) and agarononoses (A9) by AgWH50B, DagA (a). The cleavage sites of agarase AgWH50B (\&<) and DagA (\&) act on the A7 or A9 (b). The shades of scissors mean the priority of the hydrolyzed AOSs. 

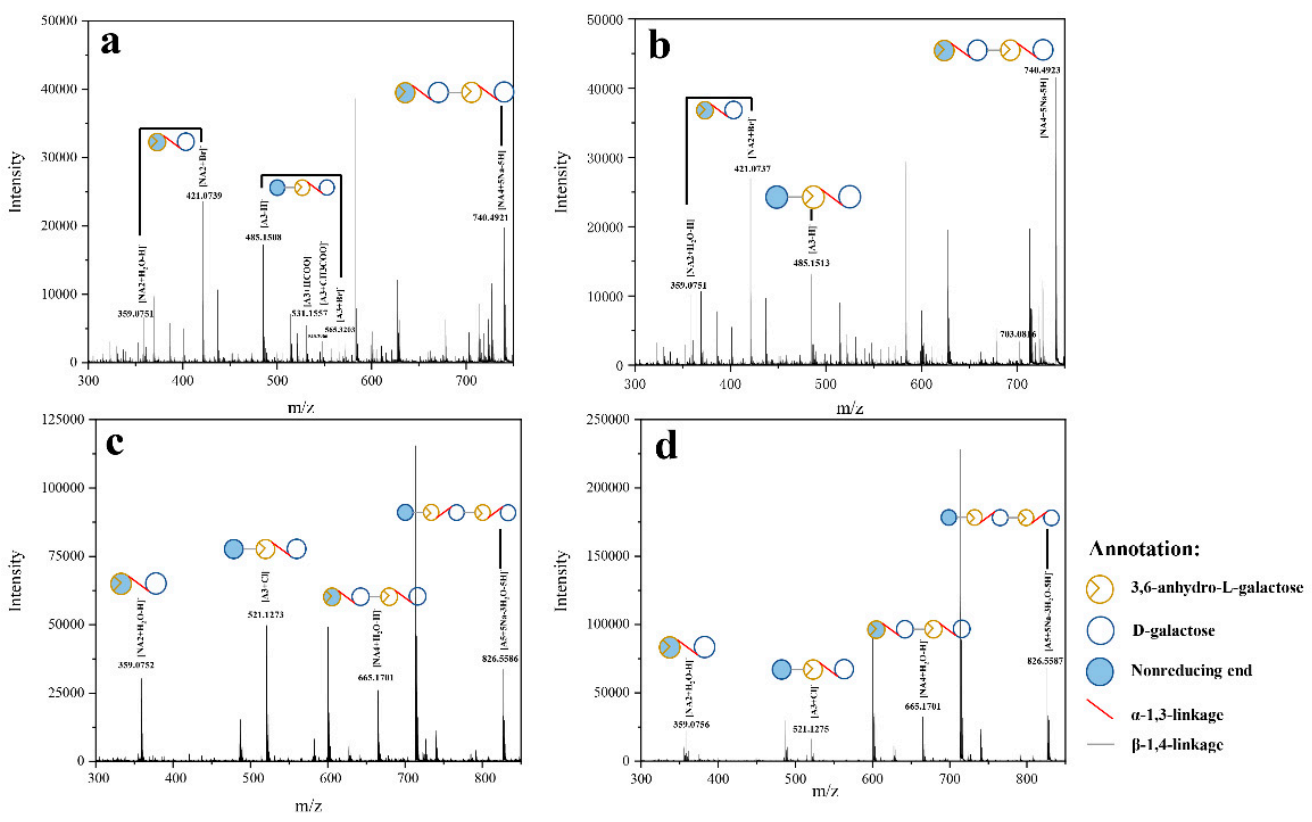

Figure 3. ESI-MS analysis of enzymatic production of agaroheptaose (A7), by AgWH50B (a) or DagA (c) and agarononoses (A9) by AgWH50B (b) or DagA (d).

\subsection{Preparation of $A 3, A 5$ by the Chemical-Biological Route}

As shown in Figure 4, in the Step II of the chemical-biological route, the yield of A3 was increased with the enzyme amount raising from $0.244 \mathrm{U} / \mathrm{mL}$ to $1.950 \mathrm{U} / \mathrm{mL}$. However, there is no significant increase of the yield of A3 when AgWH50B amount was improved to $2.925 \mathrm{U} / \mathrm{mL}$. Therefore, $1.950 \mathrm{U} / \mathrm{mL}$ $\mathrm{AgWH} 50 \mathrm{~B}$ was chosen as the optimum enzyme amount for the preparation of A3. In addition, the yield of A3 and A5 from combining acidolysis with DagA catalysis was increased with the increase of enzyme amount during 0.0238-0.1900 U/mL DagA, and the yield increase of A3 and A5 was not obvious when using $0.2850 \mathrm{U} / \mathrm{mL}$ DagA. Therefore, $0.1900 \mathrm{U} / \mathrm{mL}$ DagA was chosen as the optimum enzyme amount for the preparation of A3 and A5. Furthermore, the processes of A3 or both A3 and A5 production were shown in Figure $5 b, c$, respectively. A3 was gradually produced during the enzymatic hydrolysis by AgWH50B. A volume of $85.50 \pm 0.02 \mathrm{~g} / \mathrm{L}$ A3 was obtained after enzymatic hydrolysis for $24 \mathrm{~h}$ in $10 \mathrm{~mL}$ reaction mixture, which means $0.855 \pm 0.020 \mathrm{~g} \mathrm{~A} 3$ was produced from $1.5 \mathrm{~g}$ agarose. Moreover, A3 and A5 were gradually produced during enzymatic hydrolysis by DagA. A volume of $23.30 \pm 2.01 \mathrm{~g} / \mathrm{L} \mathrm{A} 3$ and $22.80 \pm 0.22 \mathrm{~g} / \mathrm{L} \mathrm{A} 5$ were obtained after enzymatic hydrolysis in $10 \mathrm{~mL}$ reaction mixture, which means $0.233 \pm 0.020 \mathrm{~g} \mathrm{~A} 3$ and $0.228 \pm 0.002 \mathrm{~g}$ A5 were produced from $1.5 \mathrm{~g}$ agarose. As shown in Figure 5a, there are no AOSs smaller than DP4 were produced after acidolysis by citric acid. After further enzymatic hydrolysis of the neutralized solution, a large amount of A3 was produced by AgWH50B, and A3 and A5 became the major components after catalysis by DagA. However, it showed that there still exist byproducts; therefore, removing these byproducts is important in the following step for the purification of A3 or A5. 

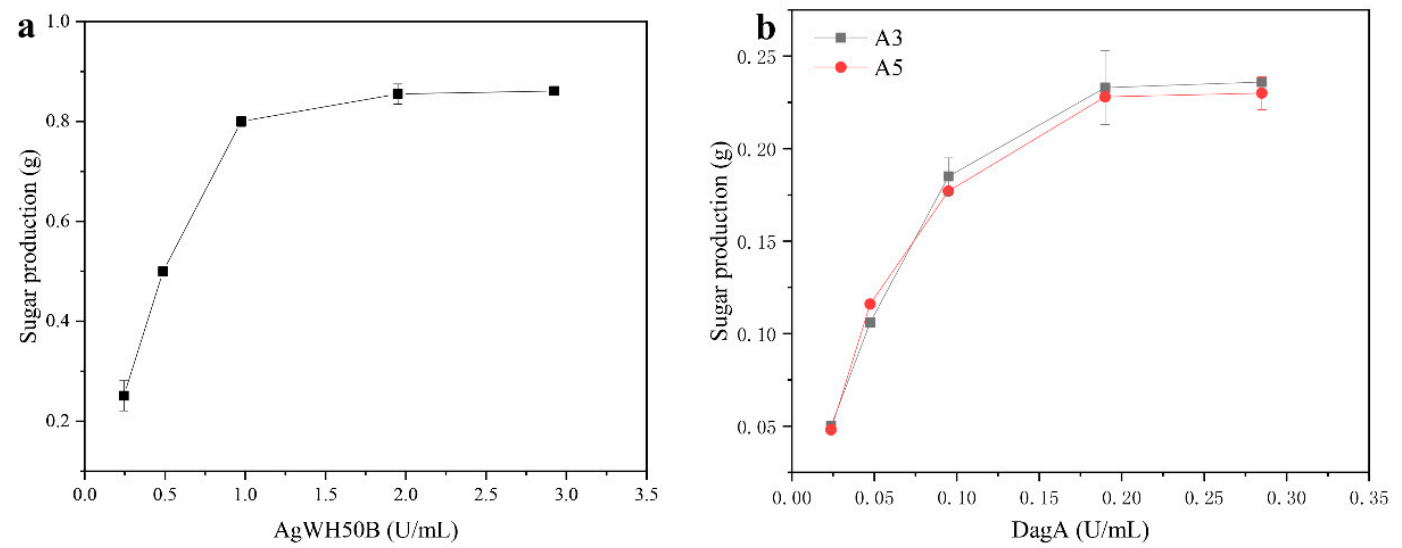

Figure 4. The optimization of enzyme amount for producing A3 (a) or both A3 and A5 (b). The value of each point was the mean of three experiments $(n=3)$. Error bars represent one standard deviation of triplicate measurements.
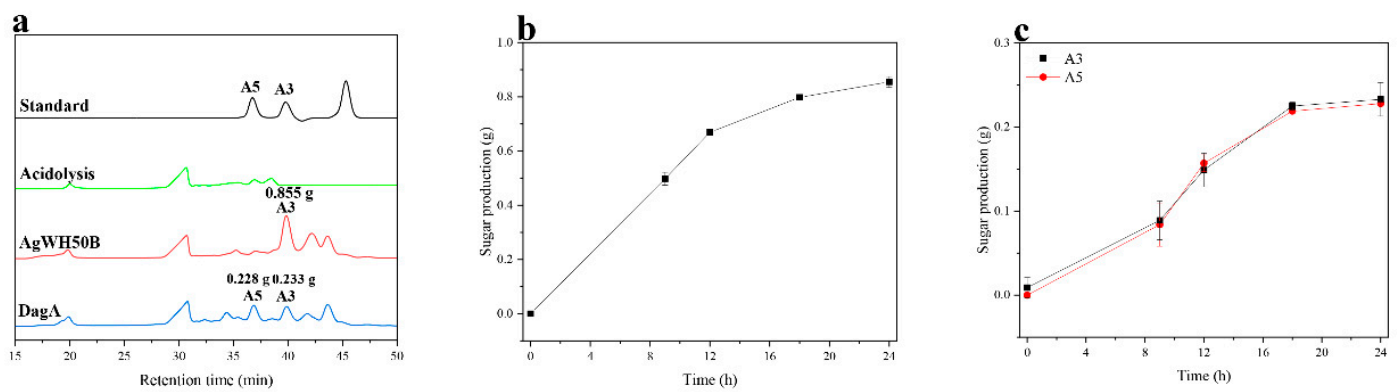

Figure 5. HPLC analysis of AOSs production during the chemical-biological route (a). Time-course of the product formation during the processes of enzymatic hydrolysis by AgWH50B (b) or DagA (c). The value of each point was the mean of three experiments $(n=3)$. Error bars represent one standard deviation of triplicate measurements.

\subsection{Purification of $A 3, A 5$}

To remove the byproducts of crude A3 solution prepared by AgWH50B or A3 and A5 solution prepared by DagA, the Bio-Gel P2 chromatography was used for purification [2,21]. Purified A3 prepared by AgWH50B and A3, A5 prepared by DagA were collected after purification process. The aliquots containing target oligosaccharides were identified by TLC and then freeze-dried to obtain oligosaccharides powder. In this way, $0.727 \mathrm{~g} \mathrm{~A} 3$ powder could be prepared by AgWH50B and $0.212 \mathrm{~g} \mathrm{A3}, 0.206 \mathrm{~g}$ A5 powder could be prepared by DagA in total. This means that the yield of A3 prepared by AgWH50B was 48\%, the yields of A3 and A5 prepared by DagA were $14 \%$ and $13 \%$, respectively. Purified powders were dissolved with certain volume of ultrapure water, then analyzed by HPLC and ESI-MS. These results suggested that the purified A3 and A5 were acquired successfully (Figure 6). According to the results of HPLC, the amount of A3 prepared by AgWH50B was $0.700 \mathrm{~g}$ with a purity of $96.23 \%$, and the amounts of A3 and A5 prepared by DagA were $0.203 \mathrm{~g}$ and $0.200 \mathrm{~g}$ with the purity of $95.89 \%$ and $97.09 \%$, respectively.

AgWH50B is a NA4-forming $\beta$-agarase, which can act on the first $\beta-1,4$ bond from the non-reducing end of agarose. NA4 would be produced when the substrate was agarose; however, the A3 of the agarose's non-reducing end was retained (Figure 7a). In our study, the agarose was liquefied by citric acid into AOSs because the $\alpha-1,3$-glycosidic linkages of agarose were preferentially cleaved. Therefore, when AgWH50B acts on these AOSs, A3 would be cut off from the non-reducing end of each AOS with different PD (Figure $7 \mathrm{~b}$ ). This explains why A3 is dominant in the product mixture of the NA4-producing $\beta$-agarase AgWH50B, with using the liquefied agarose as substrate. Our work 
indicates that for an enzyme-catalyzing reaction, the chemical bond acted on by the enzyme is more essential than the usually regarded product of the enzyme.
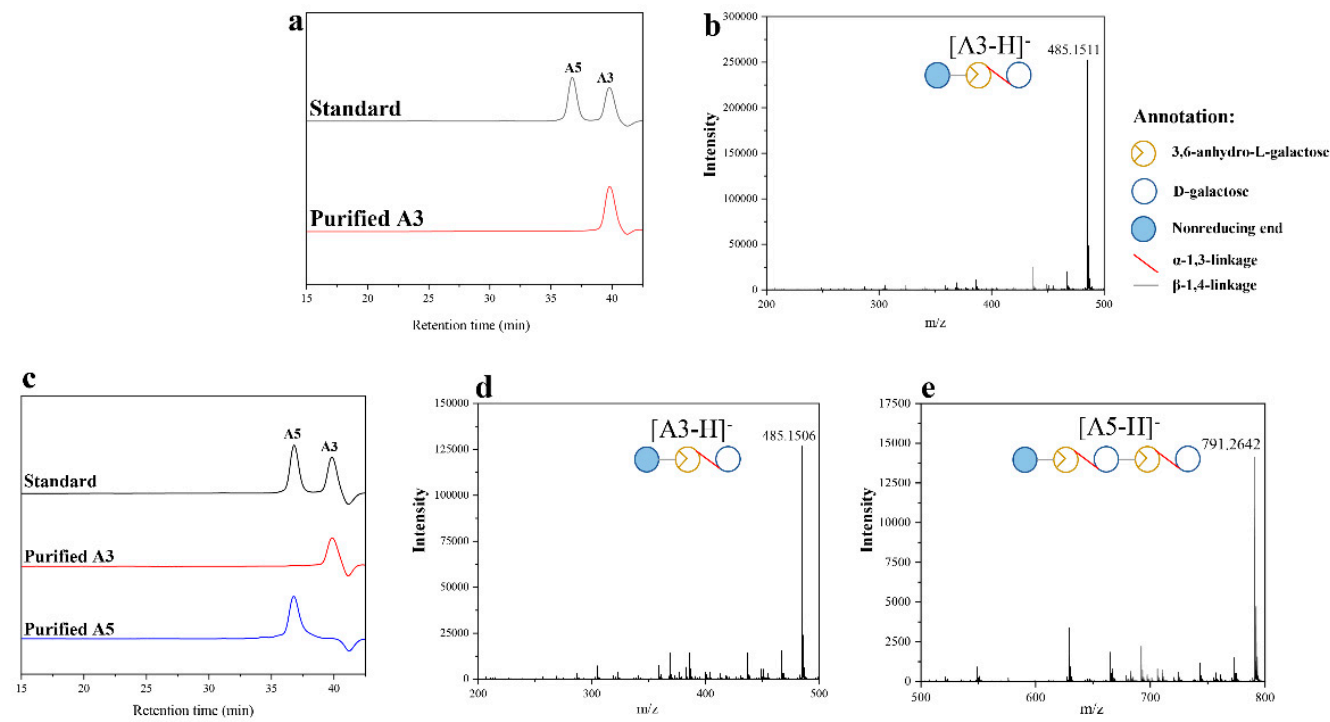

Figure 6. HPLC analysis of the obtained pure A3 produced by AgWH50B (a) and pure A3, A5 produced by DagA (c). ESI-MS analysis of the results of pure A3 produced by AgWH50B (b) and pure A3, A5 produced by DagA $(\mathbf{d}, \mathbf{e})$.

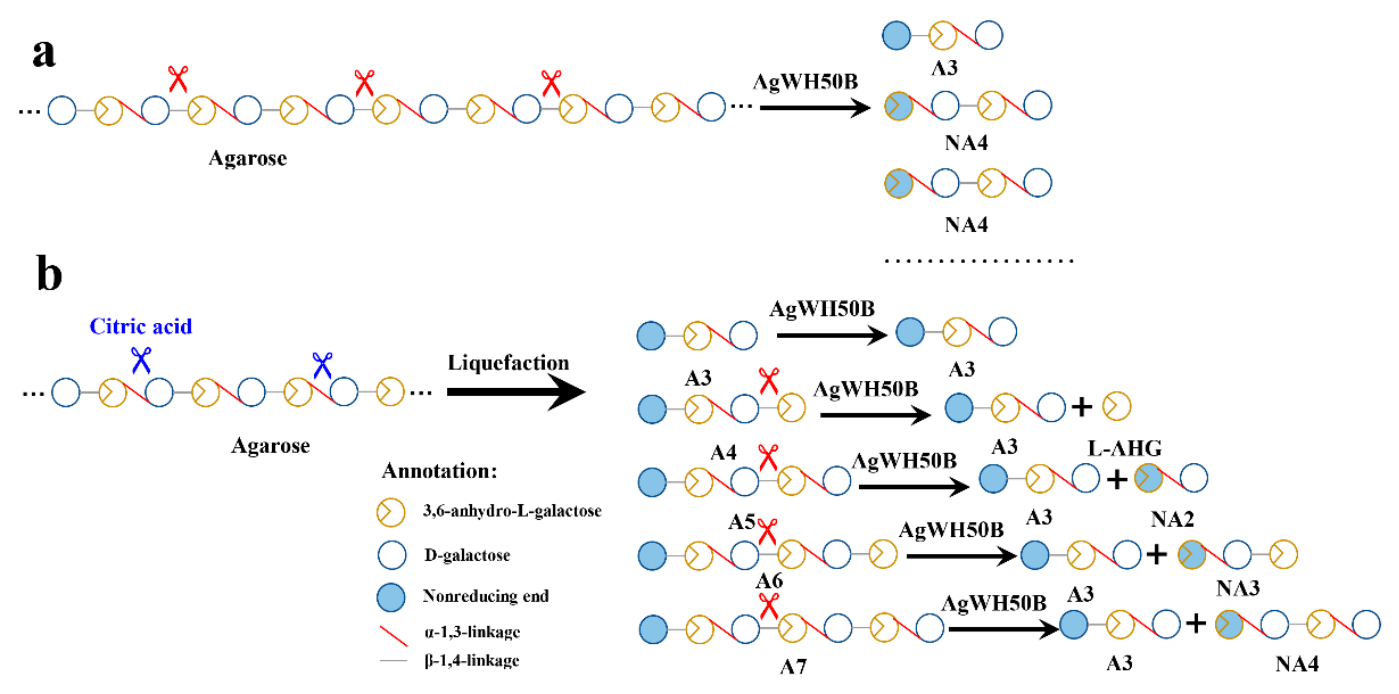

Figure 7. Comparison of simple enzymatic hydrolysis of agarose with our chemical-biological route, to show the reason of A3 accumulation. NA4 production from agarose by enzymatic hydrolysis with NA-forming $\beta$-agarase AgWH50B (a); A3 production by acid hydrolysis followed by enzymatic hydrolysis with NA-forming $\beta$-agarase $\mathrm{AgWH} 50 \mathrm{~B}$ (b).

In a previous study, a 33.2\% yield of AOSs from agar acidolysis was reported [20]. Another report indicated that acidolysis with higher acid concentration generated smaller molecular weight products with higher yield. The product DP ranges and reaction yields for different treatments were: DP 2-22, $14.5 \%(0.1 \mathrm{M} \mathrm{HCl}) ; \mathrm{DP} 2-16,28.3 \%(0.2 \mathrm{M} \mathrm{HCl}) ; \mathrm{DP} 1-14,45,6 \%(0.4 \mathrm{M} \mathrm{HCl}) ;$ and DP $1-6,47.0 \%$ $(0.8 \mathrm{M} \mathrm{HCl})$. According to a recent report, $20.51 \%$ AOSs were produced through cellulase hydrolysis from $0.25 \%$ agarose; the AOSs produced by acidolysis were an extremely complex mixture [22]. Moreover, in our previous study, the $\beta$-agarase AgWH50B and a $\alpha$-neoagarobiose hydrolase (NABH) AgWH117A were combined for obtaining pure A3 from 0.3\% low-gelling-temperature agarose [23,24]. These results indicated the low yield of AOSs production and the complexity of separating products 
from acidolysis agarose or agar. In addition, preparation of pure AOS through single enzymatic hydrolysis is efficient only when the substrate concentration is very low, which then contributes to a low output. Compared with these studies, for the above problems, our study combined these two ways and then provided a specific and efficient method for preparation of pure AOSs, which is not only suitable for A3 and A5 but also can be used for preparation of odd-numbered AOSs with higher DP, as long as the suitable enzyme was used.

\section{Materials and Methods}

\subsection{Materials}

Agarose for A3, A5 production was purchased from TsingKe (Beijing, China). Escherichia coli BL21(DE3) was used for expression of AgWH50B (GenBank accession no. KY417136) and DagA (GenBank accession no. CAA29257.1) with plasmid pET21a (+). The citric acid monohydrate for pretreating the agarose was ordered from Chinese Medicine Ltd (Qingdao, China). Yeast extract and tryptone used for medium were purchased from Oxoid (Basingstoke, England). A3, A5, A7, and A9 were obtained from Bz Oligo Biotech (Tsingtao, China).

\subsection{Acidolysis}

Agarose $(15 \% \mathrm{w} / \mathrm{v})$ was dissolved in $2.5 \%(\mathrm{w} / \mathrm{v})$ citric acid monohydrate solutions with a total reaction mixture volume of $200 \mathrm{~mL}$. The acidolysis process was performed at $90{ }^{\circ} \mathrm{C}$ and $0.5 \mathrm{MPa}$ for 50 min using a Ldzx-50kbs vertical pressure steam sterilizer from Shenan Medical Apparatus Plant (Shanghai, China). After cooling down to room temperature, the reaction mixture was neutralized to pH 7.0 with $20 \%$ (w/v) sodium hydroxide.

\subsection{Preparation of $A g W H 50 B$ and $D a g A$}

The E. coli BL21(DE3) harboring pET21a (+)-agWH50B or pET21a (+)-dagA were cultured at Luria-Bertani (LB) medium ( $1 \%$ peptone, $0.5 \%$ yeast extract, and $1 \% \mathrm{NaCl})$, shaking at $37{ }^{\circ} \mathrm{C}$ and $200 \mathrm{rpm}$ for $12 \mathrm{~h}$ [25]. Then, transfer to fermentation medium ZYP-5052 (1\% tryptone, $0.5 \%$ yeast extract, $0.2 \% \mathrm{MgSO} 4,1.25 \%$ glycerol, $0.125 \%$ glucose, and $10 \% \alpha$-galactose), shaking (220 rpm) for $48 \mathrm{~h}$ at $20^{\circ} \mathrm{C}$. The cell was collected by centrifugation at $8000 \times \mathrm{g}$ for $15 \mathrm{~min}$ at $4{ }^{\circ} \mathrm{C}$, per $100 \mathrm{~mL}$ of fermentation broth was resuspended in $20 \mathrm{~mL}$ acid-base buffer (20 mM PBS buffer, pH 7.0) and subsequently disrupted for at a cycle for 30 minutes by Ultrasonic cell wall breaking instrument from Xinzhi Biotechnology Co., Ltd (Ningbo, China); the cycle program was on for 0.3 seconds and off for 0.3 seconds lasting for $30 \mathrm{~min}$. The crude extracts were obtained by centrifugation at $8500 \times g$ for $15 \mathrm{~min}$ at $4{ }^{\circ} \mathrm{C}$, then freeze-dried to get the crude enzyme powder. Powder $(3 \mathrm{~g})$ could be obtained per litre fermentation medium.

\subsection{Enzyme Assay}

The concentrations of reducing sugars were determined by 3,5-dinitrosalicylic acid (DNS) method [26]. One unit of enzymatic activity (U) was defined as the amount of enzyme that produced $1 \mu \mathrm{mol}$ of reducing sugar per min by hydrolyzing agarose. The crude enzyme activity of AgWH50B and DagA were $0.195 \mathrm{U} / \mathrm{mg}$ and $0.019 \mathrm{U} / \mathrm{mg}$, respectively. The amount of AgWH50B and DagA was optimized for the last reaction to prepare A3, A5. 0.244, 0.488, 0.975, 1.950, $2.925 \mathrm{U} / \mathrm{mL}$ AgWH50B, and $0.0238,0.0475,0.0950,0.1900,0.2850 \mathrm{U} / \mathrm{mL}$ DagA were used for the optimization with a $10 \mathrm{~mL}$ reaction volume at $40{ }^{\circ} \mathrm{C}$ for $12 \mathrm{~h}$. All measurements were performed in triplicate.

\subsection{Preparation of $A 3, A 5$}

Taking the neutralized oligosaccharides solution obtained by acidolysis as the substrate, we prepared A3 and A3, A5 respectively from AgWH50B and DagA enzymolysis with a total volume of $10 \mathrm{~mL}$ at $40{ }^{\circ} \mathrm{C}$ for $24 \mathrm{~h}$. At the same time, we optimized the enzyme amount of AgWH50B and DagA to 
realize producing target oligosaccharides with relative lower cost. After reaction, the reaction mixture was boiled for $10 \mathrm{~min}$ followed by centrifuging at $8500 \times \mathrm{g}$ for $20 \mathrm{~min}$ to obtain crude sugar solution.

\subsection{Purification of $A 3, A 5$}

In order to obtain pure A3 and A5. The crude sugar solution from the part 2.4 was separated by Bio-Gel P2 chromatography column eluting by hyperpure water with the rate of $1 \mathrm{~mL} / \mathrm{min}$. Aliquots were sampled every $5 \mathrm{~min}$; ingredient of every sample was determined by thin layer chromatography (TLC), the plates were eluted in a developing solvent composed of n-butanol/acetic acid/water $(2: 1: 1, \mathrm{v}: \mathrm{v}: \mathrm{v})$. The spots were visualized by soaking in an ethanol solution containing $10 \%(\mathrm{v} / \mathrm{v}) \mathrm{H}_{2} \mathrm{SO}_{4}$, then coloration by heating at $100{ }^{\circ} \mathrm{C}$ for $5 \mathrm{~min}$. The purified samples were further analyzed through high performance liquid chromatography (HPLC) with a Superdex 30 increese 10/300 gel filtration column (GE Health, Marlborough, MA, USA) with $5 \mathrm{mM}$ ammonium formate as the mobile phase at a flow rate of $0.4 \mathrm{~mL} / \mathrm{min}$; the detector was a refractive index detector (RID) (Agilent, USA) [27]. Furthermore, the molecular weight of each sample was determined using the ESI-MS method on microTOF-Q II equipment (Agilent, USA) in a negative mode with ion spray voltage of $4 \mathrm{kV}$ and source temperature of $350{ }^{\circ} \mathrm{C}$.

\section{Conclusions}

In summary, this study successfully employed a specific and efficient method for production of pure $\mathrm{A} 3$ and $\mathrm{A} 5$ with NAOS-producing $\beta$-agarase as catalyst. By using citric acid to produce AOSs with high DP and then NA4-forming $\beta$-agarase AgWH50B from A. gilvus WH0801 and NA4, NA6-forming $\beta$-agarase DagA from S. coelicolor A3(2) was used to hydrolyze the AOSs with high DP for preparation of A3 or both A3 and A5, respectively. Moreover, it is indicated that our method has potential for the production of odd-numbered AOSs with higher DP.

Author Contributions: Conceptualization, C.J. and X.M.; methodology, C.J. and Z.L.; software, J.S. and C.X.; validation, C.J. and C.X.; data curation, C.J. and J.S.; writing-original draft preparation, C.J.; writing-review and editing, Z.L.; visualization, J.S.; supervision, Z.L.; project administration, X.M.; funding acquisition, X.M. All authors have read and agreed to the published version of the manuscript.

Funding: This work was supported by the National Key R\&D Program of China (2018YFC0311200), the Taishan Scholar Project of Shandong Province (tsqn201812020), and Fundamental Research Funds for the Central Universities (201941002).

Conflicts of Interest: The authors declare no conflict of interest.

\section{References}

1. Lahaye, M.; Yaphe, W.; Viet, M.T.P.; Rochas, C. 13 C-n.m.r. spectroscopic investigation of methylated and charged agarose oligosaccharides and polysaccharides. Carbohydr. Res. 1989, 190, 249-265. [CrossRef]

2. Li, J.; Han, F.; Lu, X.; Fu, X.; Ma, C.; Chu, Y.; Yu, W. A simple method of preparing diverse neoagaro-oligosaccharides with $\beta$-agarase. Carbohydr. Res. 2007, 342, 1030-1033. [CrossRef]

3. Chen, H.M.; Zheng, L.; Yan, X.J. The preparation and bioactivity research of agaro-oligosaccharides. Food Technol. Biotechnol. 2005, 43, 29-36.

4. Jin, M.; Liu, H.; Hou, Y.; Chan, Z.; Di, W.; Li, L.; Zeng, R. Preparation, characterization and alcoholic liver injury protective effects of algal oligosaccharides from Gracilaria lemaneiformis. Food Res. Int. 2017, 100, 186-195. [CrossRef]

5. Ramnani, P.; Chitarrari, R.; Tuohy, K.; Grant, J.; Hotchkiss, S.; Philp, K.; Campbell, R.; Gill, C.; Rowland, I. In vitro fermentation and prebiotic potential of novel low molecular weight polysaccharides derived from agar and alginate seaweeds. Anaerobe 2012, 18, 1-6. [CrossRef]

6. Ye, Q.; Wang, W.; Hao, C.; Mao, X. Agaropentaose protects SH-SY5Y cells against 6-hydroxydopamine-induced neurotoxicity through modulating NF-kB and p38MAPK signaling pathways. J. Funct. Foods 2019, 57, 222-232. [CrossRef] 
7. Ekborg, N.A.; Taylor, L.E.; Longmire, A.G.; Henrissat, B.; Weiner, R.M.; Hutcheson, S.W. Genomic and proteomic analyses of the agarolytic system expressed by Saccharophagus degradans 2-40. Appl. Environ. Microb. 2006, 72, 3396-3405. [CrossRef]

8. Yun, E.J.; Kim, H.T.; Cho, K.M.; Yu, S.; Kim, S.; Choi, I.G.; Kim, K.H. Pretreatment and saccharification of red macroalgae to produce fermentable sugars. Bioresour. Technol. 2016, 199, 311-318. [CrossRef]

9. Flament, D.; Barbeyron, T.; Jam, M.; Potin, P.; Czjzek, M.; Kloareg, B.; Michel, G. Alpha-agarases define a new family of glycoside hydrolases, distinct from beta-agarase families. Appl. Environ. Microb. 2007, 73, 4691-4694. [CrossRef]

10. Potin, P. Purification and characterization of the alpha-agarase from Alteromonas agarlyticus (Cataldi) comb. nov. strain GJ1B. Eur. J. Biochem. 1993, 214, 599-607. [CrossRef]

11. Liu, J.; Liu, Z.; Jiang, C.; Mao, X. Biochemical characterization and substrate degradation mode of a novel alpha-agarase from Catenovulum agarivorans. J. Agric. Food Chem. 2019, 67, 10373-10379. [CrossRef]

12. Kim, J.H.; Yun, E.J.; Seo, N.; Yu, S.; Kim, D.H.; Cho, K.M.; An, H.J.; Kim, J.H.; Choi, I.G.; Kim, K.H. Enzymatic liquefaction of agarose above the sol-gel transition temperature using a thermostable endo-type $\beta$-agarase, Aga16B. Appl. Microbiol. Biot. 2017, 101, 1111-1120. [CrossRef]

13. Liang, Y.; Ma, X.; Zhang, L.; Li, F.; Liu, Z.; Mao, X. Biochemical characterization and substrate degradation mode of a novel exotype beta-agarase from Agarivorans gilvus WH0801. J. Agric. Food Chem. 2017, 65, 7982-7988. [CrossRef]

14. Bibb, M.J.; Jones, G.H.; Joseph, R.; Buttner, M.J.; Ward, J.M. The agarase gene (dag A) of Streptomyces coelicolor A3(2): Affinity purification and characterization of the cloned gene product. J. Gen. Appl. Microbiol. 1987, 133, 2089-2096. [CrossRef]

15. Zhang, P.; Rui, J.; Du, Z.; Xue, C.; Li, X.; Mao, X. Complete genome sequence of Agarivorans gilvus WH0801(T), an agarase-producing bacterium isolated from seaweed. J. Biotechnol. 2016, 219, 22-23. [CrossRef]

16. Yang, B.; Yu, G.; Zhao, X.; Jiao, G.; Ren, S.; Chai, W. Mechanism of mild acid hydrolysis of galactan polysaccharides with highly ordered disaccharide repeats leading to a complete series of exclusively odd-numbered oligosaccharides. FEBS J. 2009, 276, 2125-2137. [CrossRef]

17. Kazlowski, B.; Pan, C.L.; Ko, Y.T. Separation and quantification of neoagaro- and agaro-oligosaccharide products generated from agarose digestion by beta-agarase and $\mathrm{HCl}$ in liquid chromatography systems. Carbohydr. Res. 2008, 343, 2443-2450. [CrossRef]

18. Kazlowski, B.; Pan, C.L.; Ko, Y.T. Monitoring and preparation of neoagaro- and agaro-oligosaccharide products by high performance anion exchange chromatography systems. Carbohydr. Polym. 2015, 122, 351-358. [CrossRef]

19. Henry, R.W.; Pickard, D.W.; Hughes, P.E. Citric acid and fumaric acid as food additives for early-weaned piglets. Anim. Sci. 2010, 40, 505-509. [CrossRef]

20. Chen, H.M.; Zheng, L.; Lin, W.; Yan, X.J. Product monitoring and quantitation of oligosaccharides composition in agar hydrolysates by precolumn labeling HPLC. Talanta 2004, 64, 773-777. [CrossRef]

21. Jang, M.-K.; Lee, D.-G.; Kim, N.; Yu, K.-H.; Jang, H.-J.; Lee, W.S.; Jang, J.H.; Lee, J.Y.; Lee, S.-H. Purification and characterization of neoagarotetraose from hydrolyzed agar. J. Microbiol. Biotechnol. 2009, 19, 1197-1200. [CrossRef]

22. Kang, O.L.; Ghani, M.; Hassan, O.; Rahmati, S.; Ramli, N. Novel agaro-oligosaccharide production through enzymatic hydrolysis: Physicochemical properties and antioxidant activities. Food Hydrocoll. 2014, 42, 304-308. [CrossRef]

23. Liu, N.; Yang, M.; Mao, X.; Mu, B.; Wei, D. Molecular cloning and expression of a new alpha-neoagarobiose hydrolase from Agarivorans gilvus WH0801 and enzymatic production of 3,6-anhydro-1-galactose. Biotechnol. Appl. Biochem. 2016, 63, 230-237. [CrossRef]

24. Wang, Q.; Sun, J.; Liu, Z.; Huang, W.; Xue, C.; Mao, X. Coimmobilization of beta-agarase and alpha-neoagarobiose hydrolase for enhancing the production of 3,6-anhydro-l-galactose. J. Agric. Food Chem. 2018, 66, 7087-7095. [CrossRef]

25. Bertani, G. Studies on lysogenesis.1. The mode of phage liberation by lysogenic Escherichia-coli. J. Bacteriol. 1951, 62, 293-300. [CrossRef] 
26. Miller, G.L. Use of dinitrosalicylic acid reagent for determination of reducing sugar. Anal. Biochem. 1959, 31, 426-428. [CrossRef]

27. Zhu, B.; Tan, H.; Qin, Y.; Xu, Q.; Du, Y.; Yin, H. Characterization of a new endo-type alginate lyase from Vibrio sp. W13. Int. J. Biol. Macromol. 2015, 75, 330-337. [CrossRef]

(C) 2020 by the authors. Licensee MDPI, Basel, Switzerland. This article is an open access article distributed under the terms and conditions of the Creative Commons Attribution (CC BY) license (http://creativecommons.org/licenses/by/4.0/). 